\title{
Can a Brief Strength-Based Parenting Intervention Boost Self-Efficacy and Positive Emotions in Parents?
}

\author{
Lea Waters $^{1}$. Jessie Sun ${ }^{1}$
}

Accepted: 23 February 2017 / Published online: 20 March 2017

(C) Springer International Publishing AG 2017

\begin{abstract}
Although strength-based interventions have been employed with general and targeted adult samples, to date, no published research has examined the effect of strength-based interventions for parents. Given that parenting can trigger both illbeing and wellbeing outcomes, more research is needed to examine how to help parents thrive and to meet Seligman's (Am Psychol, 54(8), 559-562, 1999) early calls for the application of positive psychology in families. The current study $(N=137)$ measured the effect of a three-week strength-based parenting intervention on parental selfefficacy and positive emotions using a quasi-experimental, waitlist comparison group design. Parents were shown how to identify and cultivate strengths in themselves and their children. Compared to parents in the comparison group, parents who undertook the strength-based intervention showed gains in self-efficacy (i.e., greater confidence and perceived ability to successfully raise their children) and positive emotions when thinking about their children. These results suggest that strength-based approaches could help boost parental wellbeing. Limitations and suggestions for future research are discussed.
\end{abstract}

Keywords Strength-based parenting $\cdot$ Strengths $\cdot$ Parental wellbeing $\cdot$ Parenting intervention · Self-efficacy · Positive emotions

Parenting is a role that is joyful and rewarding, yet simultaneously stressful and difficult. Reflecting the "high-cost/high-reward" (Senior 2014, p. 6) nature of parenting, it is no surprise that the literature on the link between parenthood and wellbeing is mixed, showing that parenting can create ill-being under some circumstances and wellbeing under others (Nelson et al. 2014). Reviewing these divergent outcomes, Nelson et al. (2014) suggest that parental stressors include sleep disturbance, negative

Lea Waters

1.waters@unimelb.edu.au

1 The Centre for Positive Psychology, The University of Melbourne, Parkville, Australia 
emotions, financial burdens, and strained partner relationships, but also include the rewards of purpose and meaning in life, need satisfaction (i.e., autonomy, relatedness, and competence), positive emotions, and enrichment of one's identity.

The complexity of the parenthood-wellbeing link points to the importance of understanding the conditions that help parents to build their wellbeing and thrive in this important role. This goal aligns with a core mission of positive psychology - the promotion of flourishing families - which featured in the presidential speech (Seligman 1999) and seminal article (Seligman and Csikszentmihalyi 2000) that launched the field.

A range of demographic and psychological factors influence parental wellbeing: for instance, parents who are older at the birth of their first child, are married, have greater social support, and have children with easy temperaments tend to have greater wellbeing (Nelson et al. 2014). Some of these factors are clearly more amenable to intervention than others. In particular, the attitudes, mindsets, and strategies that parents bring to their role (henceforth, referred to as parenting approaches) are factors that parents have direct control over, and, as such, are able to intentionally modify.

Despite this, few studies have investigated whether helping parents to modify their parenting approaches can be used to boost their wellbeing. In fact, empirical investigation into parenting is noticeably absent in the field of positive psychology. Indeed, large scale reviews of the field show that while positive psychology research has made its way into institutions such as workplaces and schools it does not yet feature in the institution of family (Donaldson and Dollwet 2015; Rusk and Waters 2013). Recently, the first author coded all published papers in the Journal of Positive Psychology from its inception in 2006 to the end of 2016 to establish the percentage of articles that had studied parenting. Published papers on parenting were completely absent for 6 of those years. In the years where parenting papers where published, they ranged from 5\% to $2 \%$ of total publications. The average number of parenting papers published in the Journal of Positive Psychology over the past decade was 1.6\%. Adding to this, the first author was the Chair of the Scientific Committee for the 4th World Congress on Positive Psychology. While the congress received over 380 submissions, only 5 were focused on parenting $(1 \%)$ and only two of those submissions were accepted on to the congress program. What these figures point to is the fact that, despite the early calls by Seligman to study the application of positive psychology in families, the topic of parenting has been poorly represented in the field. Given the importance of effective parenting to a flourishing society, this omission is concerning.

The current paper addresses this gap by investigating whether a brief strength-based parenting (SBP) intervention can enhance parental self-efficacy (i.e., a parent's confidence and perceived competence in their ability to parent successfully; Jones and Prinz 2005; Johnston and March 1989) and the extent to which parents feel positive emotions when thinking about their children.

\section{Parenting Approaches and Parent Wellbeing}

Differences in parenting approaches may provide one key to understanding what contributes to parent wellbeing. For example, some parents have a stronger subjective sense that childrearing is their calling: they see parenting as their destiny and an 
important part of who they are, think about their children a lot, and are passionate about parenting (Coulson et al. 2012). Calling-oriented parents report greater pleasure and satisfaction from parenting, greater positive affect, and are less likely to report that parenting is a burden.

Similarly, parenting appears to be more rewarding for parents who have a strong desire to provide for a child's welfare. Child-centrism describes a mindset in which parents are motivated to maximizing their child's wellbeing by prioritizing the allocation of their personal resources (e.g., time, money, attention) to their children, even if it means sacrificing their own pleasures and pursuits (Ashton-James et al. 2013). Through a day reconstruction study, Ashton-James et al. (2013) found that child-centric parents reported higher levels of positive affect, lower levels of negative affect, and higher levels of meaning when taking care of their children (but not during other daily activities).

The related construct of parental communal strength describes the extent to which parents care about their children's welfare and are willing to incur costs to meet their children's needs (Le and Impett 2016). Relative to less communally-oriented parents, Le and Impett (2016) found that highly-communal parents reported greater emotional wellbeing, relationship quality, and ability to meet their child's needs during caregiving episodes, and that this was because they felt more authentic.

Parents vary naturally in their willingness to prioritize their child's needs, their level of communal motivation, and the extent to which they see their parenting role as a calling. However, just as employees can "craft their jobs" to develop calling orientations towards their work (Wrzesniewski and Dutton 2001), Coulson et al. (2012) suggest it may be possible to develop calling orientations towards one's parenting role. Experimentally demonstrating the possibility and wellbeing benefits of changing parenting approaches, Le and Impett (2016) showed that parents who were asked to think about a recent time when they provided care to their child out of concern for the child's needs (high communal strength) reported greater authenticity, emotional wellbeing, and relationship quality than parents who were instructed to think about a time when they provided care out of obligation and because it was their job (low communal strength). Although this was a one-off experimental manipulation, these findings demonstrate that it is, in principle, possible to modify parenting approaches to improve parental wellbeing.

\section{Strength-Based Parenting, Parenting Self-Efficacy, and Positive Emotions}

So far, we have seen that parents who identify with their roles and who take an altruistic attitude to parenting feel more competent and derive greater pleasure from their roles. The current paper draws on strength-based foundations from positive psychology (Seligman and Csikszentmihalyi 2000) and family wellbeing (Newland 2015; Sutton 2016) to examine whether another parenting approach-strength-based parenting (SBP) — may help parents to reap similar benefits.

Strengths can be broadly defined as skills and behaviors that feel natural and enjoyable to an individual, and allow them to perform at their best (Govindji and Linley 2007; Quinlan and Swain 2012; Sheldon et al. 2015; Wood et al. 2011). Waters (2015a) previously defined SBP as an approach to parenting that seeks to deliberately 
identify and cultivate strengths (positive states, processes, and qualities) in one's children. We introduce a third component to the SBP framework: parent strengths deployment. Building on the work of Littman-Ovadia and Steger (2010), strengths deployment can be described as the extent to which individuals use strengths within a given role. In the context of SBP, deployment is the degree to which parents put their strengths into action while raising their children (e.g., the creative parent who helps make costumes for their child's school performance, the prudent parent who helps their teenager set a monthly budget, the sporty parent who coaches their child's sporting team, the zestful parent who helps their child plans their party).

SBP features the same commitment to a child's wellbeing that calling, child-centric, and communal orientations towards parenting share in common. However, whereas the latter approaches tend to focus on meeting the child's needs (through emphasizing a strong sense of purpose and/or self-sacrifice from the parent), SBP distinguishes itself by focusing on the child's strengths. This involves a deliberate shift towards noticing a child's strengths, providing opportunities that allow the child to cultivate their strengths, and thinking about how to bring one's own strengths to parenting. SBP also distinguishes itself by focusing on the parent's strengths, not just on the child's needs.

Previous research by Waters and her colleagues found that SBP (operationalized without the deployment component) is associated with various indicators of wellbeing in children and adolescents including increased life satisfaction, increased positive affect and decreased stress (Jach et al. 2017; Waters 2015a, 2015b) To date, however, no study has examined whether SBP can enhance the wellbeing of parents. Below, we outline the ways that SBP could help parents to achieve greater wellbeing. In this study, we specifically focus on two indicators of wellbeing: parent self-efficacy and positive emotions.

Parent self-efficacy is defined as the degree to which a parent feels competent and confident in raising their children and handling problems (Johnston \& Mash, 1980). High levels of parent self-efficacy are positively associated with coping, persistence and satisfaction in the parenting role (Ardelt and Eccles 2001; Jones and Prinz 2005), whereas low levels of parent self-efficacy are related to stress and depression (Bugental and Happaney 2002; Bugental and Shennum 1984; Raikes and Thompson 2005). The link between strengths use and self-efficacy has been demonstrated in general adult samples (Govindji and Linley 2007; Proctor et al. 2011a; b), but has not, to our knowledge, been tested in a parent sample or using a strengths intervention design.

How might each aspect of SBP enhance parental self-efficacy? First, by identifying and cultivating strengths in one's children, parents may more frequently notice the ways in which their parenting efforts are helping to develop their child in positive ways such as building skills, talents, character and positive qualities in their children, thus giving them confidence in the outcomes of their parenting activities. Second, strengthbased parents are also likely to see increases in their children's wellbeing associated with greater strengths use (e.g., Proctor et al. 2011a, b; Quinlan et al. 2015; Waters 2015b) which helps them feel that their parenting is effective. Third, by learning to identify their child's strengths, parents may feel like they understand their children better and are therefore better able to meet their individual needs, thus leading to greater feelings of competence and confidence.

The SBP-self-efficacy relationship may also arise when parents see and use their own strengths. Given that strengths are thoughts, feelings, and actions that are performed well (Govindji and Linley 2007; Wood et al. 2011), it seems likely that parents who deploy 
their strengths while parenting will perform the role more effectively, thus boosting their sense of competence. Additionally, knowing and using strengths provides parents with a greater understanding of how their personal resources can assist them each day in raising their children, thus making them more confident in their parenting decisions.

As well as parental self-efficacy, SBP could also be associated with increased positive emotions in parents. By shifting focus towards identifying and cultivating the child's strengths (and away from a focus on the child's weaknesses), parents can open themselves to feelings such as pride, interest, joy, wonder, curiosity, and hope as they witness their child's positive growth. For example, parents who notice their children's kindness may experience feelings of elevation in response to their children's acts of virtue (Haidt 2003) and authentic pride in their children's positive actions (Tracy and Robins 2007).

Using strengths themselves as a parent could also enhance positive emotions. Supporting this possibility, using strengths has been theorized to be an energizing experience (Clifton and Anderson 2002; Peterson and Seligman 2004), and has been linked with increased positive emotions and happiness across survey, daily diary, and intervention studies with general adult populations (e.g., Lavy and Littman-Ovadia 2016; Lavy et al. 2014; Seligman et al. 2005; Wood et al. 2011).

\section{The Present Study}

The present study is the first to examine the initial parental wellbeing effects of a brief SBP intervention that features the three components of (1) learning to notice a child's strengths, (2) learning how to encourage children to use their strengths, and (3) deploying one's own strengths while parenting. We hypothesize that parents who participate in a SBP intervention will report greater levels of (H1) parental selfefficacy and (H2) positive emotions associated with their children after the intervention, relative to parents in a waitlist comparison group.

\section{Method}

\section{Participants}

A community sample of 137 Australian parents $\left(M_{\text {age }}=46.42, S D=3.56 ; 65 \%\right.$ mothers) participated in this study. Participants were recruited through SBP workshops that were facilitated by the first author (a registered psychologist), at no financial cost to the participants. Given that it was a community sample, there were no inclusion or exclusion criteria and parents were not paid to be part of the study. Implied consent was used by parents voluntarily completing the surveys pre and post the intervention.

The majority of participants were born in Australia $(n=113,82.5 \%)$, with remaining participants from New Zealand $(n=4)$, Iran $(n=4)$, England $(n=2)$, Wales $(n=2)$, Scotland $(n=2)$, U.S. $(n=2)$, Pakistan $(n=2)$, Greece $(n=2)$, Sri Lanka $(n=2)$, and India $(n=2)$. Educational backgrounds included $15 \%$ who had not completed high school, $57 \%$ high school graduates, $26 \%$ who had completed a university degree, and $2 \%$ who had completed a higher university degree. On average the parents has 2.4 children. Sixty eight percent of the parents were married and $32 \%$ were single. 


\section{Procedure and Design}

This study employed a quasi-experimental, waitlist comparison group design. As summarized in the study flow diagram (see Fig. 1), parents who signed up for the first SBP program formed the intervention group $\left(n=72 ; M_{\text {age }}=46.78, S D=3.22 ; 47.2 \%\right.$ mothers), whereas parents who signed up to the second SBP program (running 2 months later) formed the waitlist group $\left(n=65 ; M_{\text {age }}=46.03, S D=3.89 ; 84.6 \%\right.$ mothers). ${ }^{1}$

Parents voluntarily completed the baseline parent wellbeing survey (described below) upon registering their interest for the SBP program, one month before the intervention group undertook the three week SBP program. Parents in the SBP intervention group then completed two SBP workshops (described below), separated by two weeks of practicing SBP. One week after the final workshop, parents completed the post-test wellbeing survey. Attrition was minimal: 66 (91.7\%) parents in the intervention group $\left(M_{\mathrm{age}}=47.03, S D=3.24 ; 45.5 \%\right.$ mothers $)$ and $59(90.8 \%)$ parents in the waitlist group ( $M_{\mathrm{age}}=46.44, S D=3.86 ; 83.1 \%$ mothers $)$ provided complete data at post-test. Given this minimal attrition, we chose to only analyze data from participants who completed both assessments.

\section{Intervention}

As shown in Fig. 1, the SBP intervention comprised two 90 min workshops spaced by two weeks of SBP activities. The intervention activities are summarized in Fig. 2.

Workshop 1 Workshop 1 provided parents with an introduction to the Values in Action (VIA) Character Strengths Framework. Parents were asked to complete the VIA character strengths survey (http://www.viacharacter.org/www/CharacterStrengths-Survey) before the workshop, and bring along their results. Parents discussed their results in groups of four, then identified three signature strengths that they could put to better use in their role as parents, together with three lesser strengths they would like to enhance their parenting. The inclusion of both top strengths and lesser strengths is based on Proyer et al.'s (2015) finding that adults who were randomly assigned to use their lesser strengths in a new way experienced similar improvements in wellbeing as those who used their top strengths.

Next, the facilitator used "The Strengths Exchange Website" (http://www.thestrengths-exchange.com.au) to show examples of how other parents have used their character strengths to promote positive family functioning. In the third phase of the workshop, parents were introduced to the technique of strength spotting (i.e., noticing strengths in others; Linley 2008). Parents completed the Strength Spotting Scale (Linley et al. 2010) and paired up to discuss what their score revealed about their ability and motivation to engage in strengths spotting. As part of this strength spotting technique, parents were asked to review the list of 24 VIA character strengths, pick the top five strengths they could see in their children and discuss, in pairs, concrete

\footnotetext{
${ }^{1}$ Although the waitlist group had a greater proportion of mothers (relative to the intervention group), the repeated measures design ensures that differences on the outcome variable that may be influenced by gender are already controlled for.
} 


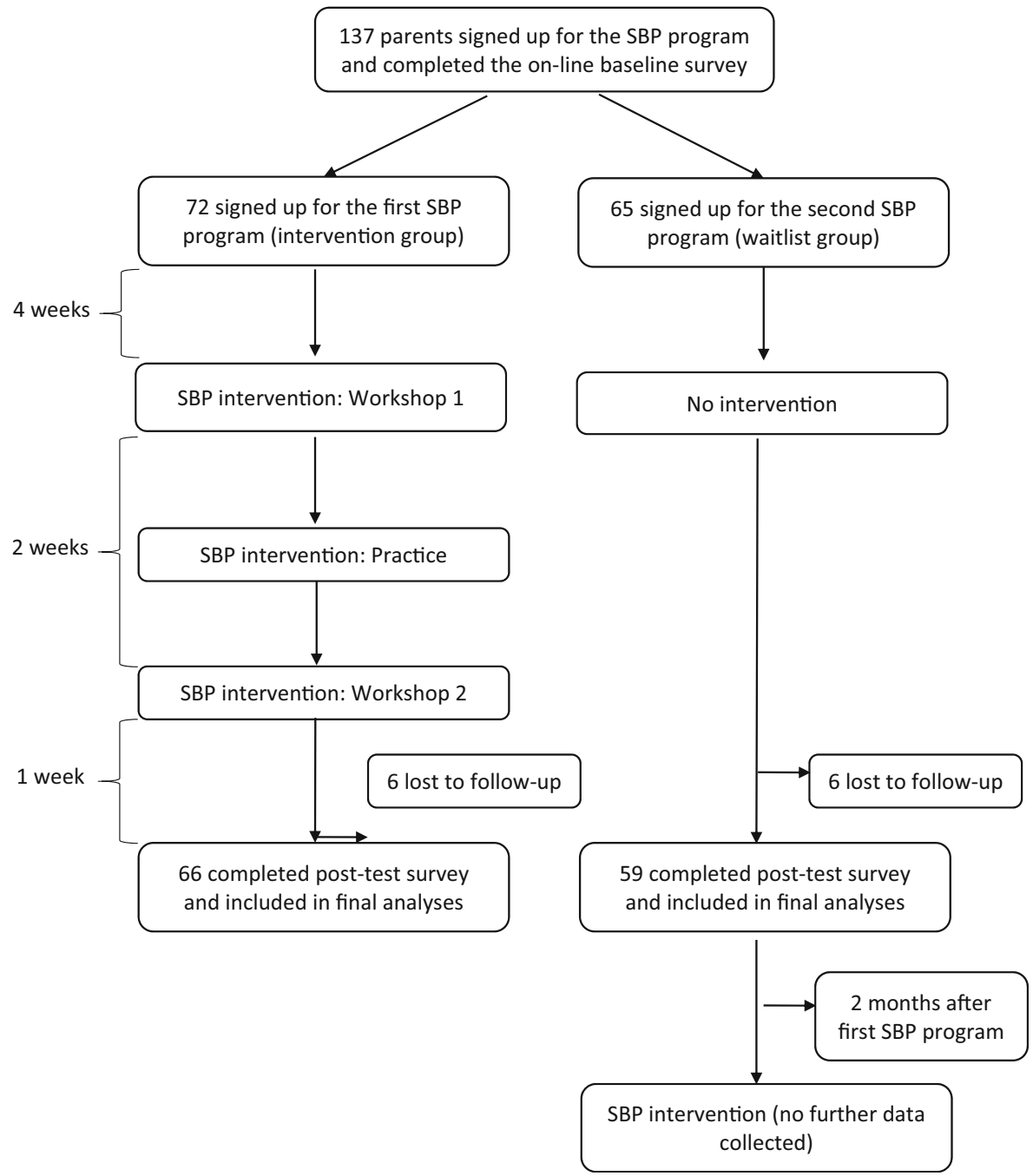

Fig. 1 Study flow diagram

examples of ways that their children had displayed the strengths they had chosen. Finally, parents practiced strength spotting using video case studies.

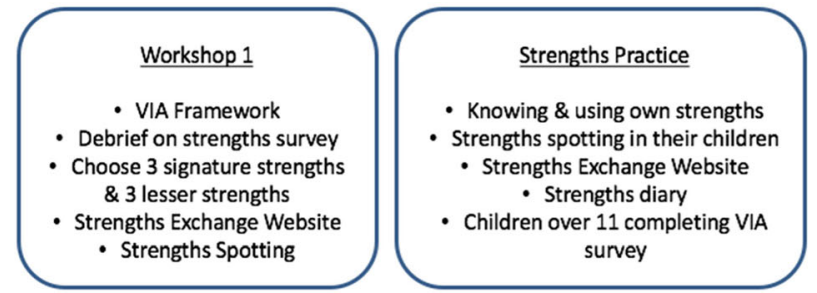

\section{Workshop 2}

- WWW debrief

- Debrief on 3 signature strengths \& 3 lesser strengths

- Strengths map

- Hindrances and helpers

- 340 ways to use strengths

Fig. 2 SBP intervention 
SBP Practice Parents were asked to practice their newly-learned SBP skills in the two weeks between the workshops. This involved the parent seeking to better know their children's strengths and encouraging their children to use their strengths. Parents were encouraged to invite their children to complete the VIA and to discuss their child's strengths profile as well as sharing their own strengths profile with their children. Parents were asked to complete a nightly diary in which they listed the strengths they had spotted in the children. To practice the parent strength deployment aspect of SBP, parents were also asked to deliberately use more of their top three strengths and more of their lesser three strengths. In addition, to promote a dynamic approach to strengths use (Biswas-Diener et al. 2011), a term the first author labelled as strengths flexibility in the workshops, parents were asked to keep a daily diary about how they were deploying the full range of all 24 VIA strengths in their parenting role.

Workshop 2 Workshop 2 began with a "What Went Well" exercise (Seligman et al. 2005) to help parents to debrief on their positive experiences from the past two weeks with the larger group. Parents then regrouped into their groups of four from Workshop 1 and discussed how they had used their signature strengths and developed their three lesser strengths in their parenting role over the past two weeks. Parents were then given a strengths map (a visual map of the 24 VIA character strengths developed by the first author), and asked to share the strengths they spotted in their children, along with concrete examples, in their group.

Parents discussed what helped and what hindered their ability to spot the strengths in their children. The hindrances identified by parents included not yet fully knowing all the VIA strengths, learning the new skill of strength spotting, time pressure, low energy, and poor concentration. Factors that helped included completing the VIA survey, downloading the VIA posters and putting them up in the house where they could easily be seen, watching clips from The Strengths Exchange website, setting certain times of the day to focus on strength spotting, and filling in the strength diary.

Finally, the facilitator gave parents Tayab Rashid's list of 340 ways to use your strengths (http://www.viacharacter.org/resources/tag/340-ways/) and asked parents to identify ways they could encourage their children to use each of the 24 strengths in everyday life (e.g., using zest when playing sport, using kindness with siblings, using social intelligence with friends, using curiosity for homework).

One week after the final workshop, parents were sent further readings and resources with guidance on how to be a strength-based parent, along with the link to the post-test parent wellbeing survey.

\section{Measures}

Parents completed the following measures at both baseline and post-test.

Parental Self-Efficacy Parents completed the Efficacy sub-scale of the Parenting Sense of Competence scale (PSOC; Johnston and Mash 1989). Parents rated 8 items (e.g., "I honestly believe I have all the skills necessary to be a good mother/father to my child) on a 7 -point scale (1 = strongly disagree, 7 = strongly agree $)$. 
Parental Positive Emotions Positive emotions were measured using the modified Differential Emotions Scale (Fredrickson et al. 2003; Hogan et al. 2015; Waugh and Fredrickson 2006). Parents were asked “...Thinking about your child/children how often do you have each of the following". Parents rated how often they felt each of 10 emotions (amused, awe, content, joyful, grateful, hopeful, interested, love, proud, surprise) on a 7 -point scale $(1=$ never, $7=$ most of the time $)$.

\section{Data Analyses}

All analyses were deployed using SPSS Version 23. Prior to the key analyses, continuous variables were transformed to standardized $z$ scores to facilitate interpretation. To test our two hypotheses, we employed two hierarchical multiple regressions which controlled for baseline scores on the dependent variable for each analysis (Step 1), before adding condition as a dichotomous predictor ( $0=$ waitlist comparison, $1=$ intervention; Step 2$)$.

\section{Results}

\section{Preliminary Analyses}

As shown in Table 1, the parental self-efficacy scale showed acceptable internal consistency and the positive emotions measure showed good internal consistency. Independent samples $t$ tests also revealed that the intervention and comparison groups did not differ in their baseline levels of self-efficacy and positive emotions, $t \mathrm{~s}<1.72$, $p s>.089$. Self-efficacy and positive emotions were significantly positively correlated at baseline, but not post-test, for both intervention conditions. ${ }^{2}$

Inspection of histograms, Q-Q plots and boxplots revealed no systematic departures from normality, aside from a slight negative skew for positive emotions at post-test. Examination of scatterplots did not reveal any evidence for nonlinearity between pairs of independent and dependent variables. Finally, inspection of residuals revealed no evidence of heteroscedasticity. Thus, overall, the data were deemed appropriate for multiple regression analyses.

\section{Parental Self-Efficacy}

Baseline levels of parental self-efficacy did not predict post-intervention levels of selfefficacy (Table 2, Model 1, Step 1). However, controlling for baseline levels of selfefficacy, the intervention condition predicted significantly higher post-intervention parental self-efficacy scores, and explained $11 \%$ of the variance in these scores (Table 2, Model 1, Step 2). The magnitude of the $b$ coefficient reveals that the average intervention effect size was 0.71 standard deviations, with a $95 \%$ confidence interval

\footnotetext{
${ }^{2}$ We refrain from further interpreting these null correlations as they could have resulted from insufficient statistical power. For example, the point estimate of $r=.24$ for the correlation between post-intervention selfefficacy and positive emotions in the intervention group was nontrivial, but a sample size around 66 only provides $50 \%$ power to detect a correlation of this magnitude (Faul et al. 2007), and 133 participants would be needed to detect this effect with $80 \%$ power.
} 
Table 1 Descriptive statistics and intercorrelations between variables

\begin{tabular}{lllllllll}
\hline & \multicolumn{1}{l}{ Waitlist } & \multicolumn{7}{c}{ Intervention } \\
& $M$ & $S D$ & $M$ & $S D$ & 1. & 2. & 3. & 4. \\
1. Self-efficacy (T1) & 4.75 & 0.88 & 4.39 & 0.69 & .76 & $.54^{*}$ & .03 & -.04 \\
2. Positive emotions (T1) & 4.62 & 1.01 & 4.22 & 0.69 & $.32^{*}$ & .85 & -.15 & -.13 \\
3. Self-efficacy (T2) & 4.55 & 0.82 & 5.16 & 0.85 & .12 & .14 & .77 & .24 \\
4. Positive emotions (T2) & 4.68 & 1.19 & 5.28 & 0.90 & .20 & $.43^{*}$ & -.07 & .92 \\
\hline
\end{tabular}

T1 = Baseline, T2 = Post-test. Correlations below the diagonal are for parents in the waitlist comparison group; correlations above the diagonal are for parents in the intervention group. $\alpha$ reliability coefficients are shown on the diagonal in bold. ${ }^{*} p<.05$

ranging from $0.37-1.06$ standard deviations. Therefore, we found support for Hypothesis 1.

\section{Parental Positive Emotions}

We repeated the same analyses with parental positive emotions as the dependent variable. Again, baseline levels of parental positive emotions did not significantly predict positive emotions at post-test (Table 2, Model 2, Step 1). However, controlling for baseline levels of positive emotions, the intervention condition predicted significantly higher post-intervention positive emotions scores, and explained $11 \%$ of the variance in these scores (Table 2, Model 2, Step 2). The magnitude of the $b$ coefficient reveals that the average intervention effect size was 0.66 standard deviations, with a 95\% confidence interval ranging from $0.31-1.00$ standard deviations. Therefore, we also found support for Hypothesis 2 .

Table 2 Multiple regressions predicting post-intervention parenting self-efficacy (Model 1) and positive emotions (Model 2)

\begin{tabular}{llllll}
\hline & $R_{\text {adj }}^{2}$ & $b$ & $95 \%$ CI & $t$ & $p$ \\
\hline $\begin{array}{l}\text { Model 1 } \\
\text { Step 1 }\end{array}$ & .00 & & & & \\
$\quad$ Baseline self-efficacy & & -0.01 & {$[-0.20,0.19]$} & -0.07 & .943 \\
$\quad$ Step 2 & .11 & & & & \\
$\quad$ Baseline self-efficacy & & 0.08 & {$[-0.11,0.27]$} & 0.84 & .400 \\
$\quad$ Intervention condition & & 0.71 & {$[0.37,1.06]$} & 4.11 & $<.001$ \\
Model 2 & & & & & \\
$\quad$ Step 1 & .02 & & & & \\
$\quad$ Baseline positive emotions & & 0.16 & {$[-0.04,0.35]$} & 1.62 & .108 \\
Step 2 & .11 & & & & \\
$\quad$ Baseline positive emotions & & 0.22 & {$[0.05,0.43]$} & 2.54 & .013 \\
$\quad$ Intervention condition & & 0.66 & {$[0.31,1.00]$} & 3.79 & $<.001$ \\
\hline
\end{tabular}




\section{Discussion}

The triumphs and tribulations associated with childrearing vary dramatically across individual parents and on a day-to-day basis (Nelson et al. 2014). How can we help a greater number of parents to have more moments and days when they feel capable and when they feel positive about their children? Recent studies suggest that parents can improve their wellbeing by changing their approaches to parenting (Le and Impett 2016). However, heretofore, no study had investigated whether a strength-based approach - a core wellbeing promotion strategy in the positive psychology literature (Quinlan and Swain 2012) - could enhance parental wellbeing. The current study tested whether a brief strength-based parenting (SBP) intervention could improve parents' wellbeing and found that parents who participated in the intervention reported greater improvements in parental self-efficacy and positive emotions relative to parents in a waitlist comparison group.

Previous research has shown that happiness is, in part, influenced by the activities people choose to do (Emmons and McCullough 2003; Hudson and Fraley 2016; Lyubomirsky and Layous 2013). The current SBP intervention offered parents a range of new activities for boosting their wellbeing, including completing the VIA strengths survey, setting strengths-based goals, spotting their children's strengths, keeping a strengths diary, completing a strengths map, and reflecting on SBP practices with other parents. These activities helped parents add SBP strategies to their parenting toolkit and to see themselves and their children through a new strength-based lens. We now discuss the processes that may explain why parents reported higher levels of parental selfefficacy and positive emotions following the intervention.

As theorized in the introduction, parents may experience gains in self-efficacy by noticing their children's positive qualities and watching their children thrive as they use their strengths. Both of these avenues were anecdotally reported to the first author by parents over the course of the SBP intervention. Seeing one's child's strengths more clearly might lead parents to feel like they are successfully cultivating wellbeing in their children and helping their children to reach their full potential. In addition, parents had the opportunity to learn how to harness the skills and qualities that come naturally to them to their parenting role. Complementing this, parents also considered how they could develop and bring less-developed strengths to their parenting role. Together, both forms of strengths deployment may have boosted parents' self-efficacy by equipping them with an expanded range of parenting strategies.

The post-intervention increase in positive emotions may have arisen from an increased focus on their children's strengths (rather than their weaknesses), which is likely to generate positive emotions such as pride, wonder, and elevation in response to their children's skills and acts of virtue. Our results are also consistent with a broader literature which suggests that strengths use increases positive emotions because it is inherently energizing and enjoyable (e.g., Lavy et al. 2014; Peterson and Seligman 2004; Seligman et al. 2005). For the first time, we demonstrate that the strengths deployment-positive emotions link holds in the parenting context as well.

In addition to these potential mechanisms, the post-intervention increases in parents' self-efficacy and positive emotions could be mutually-reinforcing, triggering an upwards spiral of self-efficacy and positivity over time. Fredrickson's (1998, 2001) broaden-and-build theory posits that positive emotions broaden attentional and 
cognitive scopes, which helps to build personal resources. Applied to the SBP context, parents' positive emotions could help parents to notice a wider range of strengths in themselves and their children, and to think of a greater number of ways to deploy their strengths, all of which could contribute to greater self-efficacy via the mechanisms discussed above. In turn, parents who are more confident in their abilities to parent and to use SBP strategies would likely create more opportunities for experiencing the positive emotions that come from seeing the strengths in their children and using their own strengths themselves. As we did not take multiple assessments of positive emotions and self-efficacy during and after the intervention, this explanation is currently speculative. However, similar upwards spiral processes have been demonstrated in other roles (e.g., Burns et al. 2008; Otake et al. 2006).

As a preliminary "proof-of-concept" study, we recognize several limitations, including a modest sample size, self-selection of participants, and lack of long-term followup. Additionally, as we did not employ an active control group or measure changes in the three aspects of SBP, it is unclear whether the effects were due to increasing SBP strategies specifically, or through mechanisms common to many psychosocial interventions (Luborsky et al. 2002; Rosenzweig 1936), including the expectation of improvement (see Crum and Phillips 2015; Wood et al. 2010). Future studies which address these limitations would enable stronger conclusions about the generalizability and duration of the intervention effects, and shed more light on the underlying mechanisms.

This study was nevertheless the first to provide evidence that a key approach from the positive psychology literature - strength-based interventions - could be successfully applied in a parenting context to improve two distinct components of parental wellbeing. Moving forward, we see several exciting future directions for this line of research. First, employing experience sampling and day reconstruction designs alongside a SBP intervention would provide further insight as to the extent to which parents report greater self-efficacy and positive emotions during moments when they use SBP strategies with their children, and would provide the time-lagged data needed to test the upward spiral effect (see Ashton-James et al. 2013; Le and Impett 2016).

Future studies could also investigate whether parents gain greater improvements in self-efficacy and positive emotions by using a general strength-based approach, or by developing and deploying specific strengths. Güsewell and Ruch (2012) showed that specific strengths have distinct associations with specific positive emotions. For example, the strengths of zest, playfulness, and hope are strongly related to the positive emotion of joy; the strength of kindness is associated with the emotion of compassion; and strengths such as spirituality/religiosity and appreciation of beauty and excellence are associated with the positive emotion of awe. The authors also found that emotional strengths (zest, hope, bravery, humor, love, and social intelligence) have the most numerous and strongest associations with the range of positive emotions. An intriguing but so far untested possibility is that SBP approaches that develop specific strengths could enhance positive emotions to a greater extent than a general strength-based approach.

Finally, although previous studies suggest that parent- and child-rated SBP is associated with greater wellbeing in children and adolescents (Jach et al. 2017; Waters 2015a, 2015b), no study has employed a SBP intervention to causally test this link. Future studies could employ a dyadic design to investigate whether the effects of a 
SBP intervention on parent wellbeing spill over into child wellbeing (and vice-versa), and whether such spill-over effects are mediated by increases in parent and child strengths knowledge and use, or other mechanisms such as relationship quality and mindset.

\section{Conclusion}

Seligman (2002) argued that wellbeing comes through the active use of one's strengths in serving others and/or serving some greater good. Serving others is at the very essence of parenting, and raising flourishing children stands as one of the most powerful ways to contribute to the greater good of society. The current study suggests that a brief SBP intervention can enhance parental self-efficacy and positive emotions, providing a promising strategy for supporting the wellbeing of parents in this important, but strenuous, role. This new line of inquiry, therefore, responds to the early calls in the field of positive psychology to investigate flourishing families (Seligman 1999; Seligman and Csikszentmihalyi 2000) and offers a new pathway for researchers interested creating "positive institutions" in our society.

\section{Compliance with Ethical Standards}

Conflict of Interest The first author is due to launch a book on strength-based parenting in 2017 and has been an invited Keynote speaker on this topic at the 2nd Positive Education Schools Association Conference (pro-bono), the 3rd Canadian Positive Psychology Conference, (speaker honorarium) and the Festival of Positive Education (pro-bono). The first author is also a co-founder of The Strengths Exchange, a website offering free strength-based resources and tools to parents (http://www.the-strengths-exchange.com.au).

\section{Appendix}

Table 3 Percentage of articles on parenting published in Journal of Positive Psychology

\begin{tabular}{llll}
\hline Year & $\begin{array}{l}\text { Total number articles } \\
\text { (and editions) published }\end{array}$ & $\begin{array}{l}\text { Number of articles } \\
\text { published on parenting }\end{array}$ & $\begin{array}{l}\text { Percentage of } \\
\text { parenting articles }\end{array}$ \\
\hline 2016 & 56 (6 editions) & 1 & $2 \%$ \\
2015 & $50(6$ editions $)$ & 0 & $0 \%$ \\
2014 & $51(6$ editions $)$ & 1 & $2 \%$ \\
2013 & $49(6$ editions $)$ & 0 & $0 \%$ \\
2012 & $42(6$ editions $)$ & 2 & $5 \%$ \\
2011 & $49(6$ editions $)$ & 0 & $0 \%$ \\
2010 & $36(6$ editions) & 0 & $0 \%$ \\
2009 & $50(6$ editions $)$ & 2 & $4 \%$ \\
2008 & $20(4$ editions $)$ & 0 & $0 \%$ \\
2007 & $24(4$ editions $)$ & 0 & $0 \%$ \\
2006 & $19(4$ editions $)$ & 1 & $5 \%$ \\
\hline
\end{tabular}

Percentages are rounded up 


\section{References}

Ardelt, M., \& Eccles, J. (2001). Effects of mother's parental efficacy beliefs and promotive parenting strategies on inner-city youth. J Fam Issues, 22(8), 944-972. doi:10.1177/019251301022008001.

Ashton-James, C. E., Kushlev, K., \& Dunn, E. W. (2013). Parents reap what they sow: Child-centrism and parental well-being. Soc Psychol Personal Sci, 4(6), 635-642. doi:10.1177/1948550613479804.

Biswas-Diener, R., Kashdan, T. B., \& Minhas, G. (2011). A dynamic approach to psychological strength development and intervention. J Posit Psychol, 6(2), 106-118. doi:10.1080/17439760.2010.545429.

Bugental, D. B., \& Happaney, K. (2002). Parental attributions. In M. Bornstein (Ed.), Handbook of parenting, volume 3 (pp. 539-505). Mahwah, New Jersey: Lawrence Erlbaum Associates.

Bugental, D. B., \& Shennum, W. A. (1984). "Difficult" children as elicitors and targets of adult communication patterns: An attributional-behavioral transactional analysis. Monographs of the Society for Research in Child Development, 49 (Serial No. 205).

Burns, A. B., Brown, J. S., Sachs-Ericsson, N., Plant, E. A., Curtis, J. T., Fredrickson, B. L., \& Joiner, T. E. (2008). Upward spirals of positive emotion and coping: Replication, extension, and initial exploration of neurochemical substrates. Personal Individ Differ, 44, 360-370. doi:10.1016/j.paid.2007.08.015.

Clifton, D. O., \& Anderson, E. (2002). StrengthsQuest: Discover and develop your strengths in academics, career, and beyond. Washington, D.C.: The Gallup Organization.

Coulson, J. C., Oades, L. G., \& Stoyles, G. J. (2012). Parents' subjective sense of calling in childrearing: Measurement, development and initial findings. J Posit Psychol, 7(2), 83-94. doi:10.1080 /17439760.2011.633547.

Crum, A., \& Phillips, D. J. (2015). Self-fulfilling prophesies, placebo effects, and the social-psychological creation of reality. In R. Scott \& M. Buchmann (Eds.), Emerging trends in the behavioral and social sciences: An interdisciplinary, searchable, and linkable resource (pp. 1-14). Chicago: Wiley. doi:10.1002 /9781118900772.etrds0296.

Donaldson, S., Dollwet, M., \& Rao., M. (2015). Happiness, excellence, and optimal human functioning revisited: Examining the peer-reviewed literature linked to positive psychology. J Posit Psychol, 10, 185195. doi: 10.1080/17439760.2014.943801.

Emmons, R. A., \& McCullough, M. E. (2003). Counting blessings versus burdens: Experimental studies of gratitude and subjective well-being in daily life. J Pers Soc Psychol, 84, 377-389. doi:10.1037/00223514.84.2.377.

Faul, F., Erdfelder, E., Land, A. G., \& Buchner, A. (2007). G*power 3: A flexible statistical power analysis program for the social, behavioral, and biomedical sciences. Behavioural Research Methods, 39(2), 175191. doi:10.3758/bf03193146.

Fredrickson, B. L. (1998). What good are positive emotions? Rev Gen Psychol, 2(3), 300-319. doi:10.1037 /1089-2680.2.3.300.

Fredrickson, B. L. (2001). The role of positive emotions in positive psychology. The broaden-and-build theory of positive emotions. The American Psychologist, 56(3), 218-226. doi:10.1037/0003-066X.56.3.218.

Fredrickson, B. L., Tugade, M. M., Waugh, C. E., \& Larkin, G. R. (2003). What good are positive emotions in crises? A prospective study of resilience and emotions following the terrorist attacks on the United States on September 11th, 2001. J Pers Soc Psychol, 84(2), 365-376. doi:10.1037/0022-3514.84.2.365.

Govindji, R., \& Linley, P. A. (2007). Strengths use, self-concordance and well-being: Implications for strengths coaching and coaching psychologists. International Coaching Psychology Review, 2(2), 143153. doi:10.1037/t01038-000.

Güsewell, A., \& Ruch, W. (2012). Are only emotional strengths emotional? Character strengths and disposition to positive emotions. Applied Psychology: Health and Wellbeing, 4, 218-239

Haidt, J. (2003). The moral emotions. In R. J. Davidson, K. R. Scherer, \& H. H. Goldsmith (Eds.), Handbook of affective sciences (pp. 852-870). Oxford: Oxford University Press.

Hogan, C. L., Catalino, L. I., Mata, J., \& Fredrickson, B. L. (2015). Beyond emotional benefits: Physical activity and sedentary behaviour affect psychosocial resources through emotions. Psychol Health, 30(3), 354-369. doi:10.1080/08870446.2014.973410.

Hudson, N. W., \& Fraley, R. C. (2016). Changing for the better? Longitudinal associations between volitional personality change and psychological well-being Personality and Social Psychology Bulletin doi:10.1177 /0146167216637840.

Jach, H. K., Sun, J., Loton, D., Chin, T.-C., \& Waters, L. E. (2017). Strengths and subjective wellbeing in adolescence: Strength-based parenting and the moderating effect of mindset. Journal of Happiness Studies. doi:10.1007/s10902-016-9841-y. 
Johnston, C., \& Mash, E. J. (1989). A measure of parenting satisfaction and efficacy. Journal of Clinical Child Psychology, 18(2), 167-175. doi:10.1207/s15374424jccp1802_8.

Jones, T. L., \& Prinz, R. J. (2005). Potential roles of parental self-efficacy in parent and child adjustment: A review. Clin Psychol Rev, 25(3), 341-363. doi:10.1016/j.cpr.2004.12.004.

Lavy, S., \& Littman-Ovadia, H. (2016). My better self: Using strengths at work and work productivity, organizational citizenship behavior, and satisfaction. J Career Dev. doi:10.1177/0894845316634056.

Lavy, S., Littman-Ovadia, H., \& Bareli, Y. (2014). Strengths deployment as a mood-repair mechanism: Evidence from a diary study with a relationship exercise group. J Posit Psychol, 9(6), 547-558. doi:10.1080/17439760.2014.936963.

Le, B. M., \& Impett, E. A. (2016). The rewards of caregiving for communally motivated parents. Soc Psychol Personal Sci, 42, 323-336. doi:10.1177/1948550615581498.

Linley, P. A. (2008). Average to a+: Realising strengths in yourself and others. Coventry, UK: CAPP Press.

Linley, P. A., Garcea, N., Hill, J., Minhas, G., Trenier, E., \& Willars, J. (2010). Strengthspotting in coaching: Conceptualisation and development of the strengthspotting scale. International Coaching Psychology Review, 5, 165-176.

Littman-Ovadia, H., \& Steger, M. (2010). Character strengths and well-being among volunteers and employees: Toward an integrative model. Journal of Positive Psychology, 5, 419-430. doi:10.1080 $/ 17439760.2010 .516765$.

Luborsky, L., Rosenthal, R., Diguer, L., Andrusyna, T. P., Berman, J. S., Levitt, J. T., et al. (2002). The dodo bird verdict is alive and well - mostly. Clinical Psychology: Science and Practice. doi:10.1093 /clipsy/9.1.2.

Lyubomirsky, S., \& Layous, K. (2013). How do simple positive activities increase well-being? Curr Dir Psychol Sci, 22(1), 57-62. doi:10.1177/0963721412469809.

Nelson, S. K., Kushlev, K., \& Lyubomirsky, S. (2014). The pains and pleasures of parenting: When, why, and how is parenthood associated with more or less well-being? Psychol Bull, 140(3), 846-895. doi:10.1037 /a0035444.

Newland, L. A. (2015). Family well-being, parenting, and child well-being: Pathways to healthy adjustment. Clin Psychol, 19(1), 3-14. doi:10.1111/cp.12059.

Otake, K., Shimai, S., Tanaka-Matsumi, J., Otsui, K., \& Fredrickson, B. L. (2006). Happy people become happier through kindness: A counting kindnesses intervention. J Happiness Stud, 7(3), 361-375. doi:10.1007/s10902-005-3650-z.

Peterson, C., \& Seligman, M. E. P. (2004). Character strengths and virtues: A handbook and classification. Washington, DC: Oxford University Press.

Proctor, C., Maltby, J., \& Linley, P. A. (2011a). Strengths use as a predictor of well-being and health-related quality of life. J Happiness Stud, 12(1), 153-169. doi:10.1007/s10902-009-9181-2.

Proctor, C., Tsukayama, E., Wood, A. M., Maltby, J., Eades, J. F., \& Linley, P. A. (2011b). Strengths gym: The impact of a character strengths-based intervention on the life satisfaction and well-being of adolescents. $J$ Posit Psychol, 6(5), 377-388. doi:10.1080/17439760.2011.594079.

Proyer, R. T., Gander, F., Wellenzohn, S., \& Ruch, W. (2015). Strengths-based positive psychology interventions: a randomized placebo-controlled online trial on long-term effects for a signature strengths- vs. a lesser strengths-intervention. Frontiers in Psychology, 6, Article 456. doi:10.3389/fpsyg. 2015.00456

Quinlan, D., \& Swain, N. (2012). Character strengths interventions: Building on what we know for improved outcomes. J Happiness Stud, 13, 1145-1163. doi:10.1007/s10902-011-9311-5.

Quinlan, D. M., Swain, N., Cameron, C., \& Vella-Brodrick, D. A. (2015). How “other people matter" in a classroom-based strengths intervention: Exploring interpersonal strategies and classroom outcomes. $J$ Posit Psychol, 10(1), 77-89. doi:10.1080/17439760.2014.920407.

Raikes, H. A., \& Thompson, R. A. (2005). Efficacy and social support as predictors of parenting stress among families in poverty. Infant Mental Health Journal, 26, 177-190. doi:10.1002/imhj.20044.

Rosenzweig, S. (1936). Some implicit common factors in diverse methods of psychotherapy. Am J Orthopsychiatry, 6(3), 412-415. doi:10.1111/j.1939-0025.1936.tb05248.x.

Rusk, R. D., \& Waters, L. E. (2013). Tracing the size, reach, impact, and breadth of positive psychology. Journal of Positive Psychology, 8, 207-221. doi:10.1080/17439760.2013.777766.

Seligman, M. E. P. (1999). The president's address. Am Psychol, 54(8), 559-562.

Seligman, M. E. P. (2002). Authentic happiness. New York: Free Press.

Seligman, M. E. P., \& Csikszentmihalyi, M. (2000). Positive psychology: An introduction. Am Psychol, 55(1), 5-14. doi:10.1037/0003-066X.55.1.5.

Seligman, M. E. P., Steen, T., Park, N., \& Peterson, C. (2005). Positive psychology progress: Empirical validation of interventions. Am Psychol, 60, 410-421.

Senior, J. (2014). All joy and no fun: the paradox of modern parenthood. New York: Harper Collins. 
Sheldon, K. M., Jose, P. E., Kashdan, T. B., \& Jarden, A. (2015). Personality, effective goal-striving, and enhanced well-being: Comparing 10 candidate personality strengths. Personal Soc Psychol Bull, 41(4), 575-585. doi:10.1177/0146167215573211.

Sutton, C. (2016). Promoting child and parent wellbeing: How to use evidence- and strengths-based strategies in practice. London: Jessica Kingsley Publishers.

Tracy, J. L., \& Robins, R. W. (2007). The psychological structure of pride: A tale of two facets. J Pers Soc Psychol, 92(3), 506-525. doi:10.1037/0022-3514.92.3.506.

Waters, L. (2015a). Strength-based parenting and life satisfaction in teenagers. Advances in Social Science Research Journal, 2(11), 158-173. Doi: 10.14738/assrj.211.1651

Waters, L. (2015b). The relationship between strength-based parenting with children's stress levels and strength-based coping approaches. Psychology, 6, 689-699. doi:10.4236/psych.2015.66067.

Waugh, C. E., \& Fredrickson, B. L. (2006). Nice to know you: Positive emotions, self-other overlap, and complex understanding in the formation of a new relationship. J Posit Psychol, 1(2), 93-106. doi:10.1080 /17439760500510569.

Wood, A. M., Froh, J. J., \& Geraghty, A. W. A. (2010). Gratitude and well-being: A review and theoretical integration. Clin Psychol Rev, 30(7), 890-905. doi:10.1016/j.cpr.2010.03.005.

Wood, A. M., Linley, P. A., Maltby, J., Kashdan, T. B., \& Hurling, R. (2011). Using personal and psychological strengths leads to increases in well-being over time: A longitudinal study and the development of the strengths use questionnaire. Personal Individ Differ, 50(1), 15-19. doi:10.1016/j. paid.2010.08.004.

Wrzesniewski, A. M. Y., \& Dutton, J. E. (2001). Crafting a job : Revisioning employees as active crafters of their work. Acad Manag Rev, 26(2), 179-201. doi:10.5465/amr.2001.4378011. 